\title{
The Monte Carlo-Based Uncertainty Health Risk Assessment Associated with Rural Drinking Water Quality
}

\author{
Yu Deng ${ }^{1}$, Fuquan $\mathrm{Ni}^{2 *}$, Zhenguang $\mathrm{Yao}^{2}$ \\ ${ }^{1}$ Key Laboratory of Agricultural Environmental Engineering, Sichuan Agricultural University, Ya'an, China \\ ${ }^{2}$ College of Information and Engineering, Sichuan Agricultural University, Ya'an, China \\ Email: *nfq1965@163.com
}

Received June 29, 2012; revised August 2, 2012; accepted August 14, 2012

\begin{abstract}
In this study, Triangular Fuzzy-number of the Fuzzy Set Theory was introduced to reform parameters of those previous health risk assessment (HRA) models, Monte Carlo simulation parameter was applied to lower the randomness and fuzziness of the HRA system, and the Monte Carlo-United States Environmental Protection Agency (MC-EPA) model was employed to evaluate the health risk associated with water quality (HRWQ), so as to solve the uncertainty HRA associated with rural drinking water quality. Results showed that the water in Mingshan was contaminated mainly by $\mathrm{Cr}(\mathrm{VI})$, nitrate, fluoride and Fe. The health risk primarily embodied in the carcinogenic risk (CR) caused by $\mathrm{Cr}(\mathrm{VI})$ that generally exceeds the limit while little non-carcinogenic toxic effected presents. However, non-carcinogenic risk (NCR) in some water resources was high, exceeding the limit "l". The results revealed the health risk level of the water quality and the health risk degree caused by the pollutants, providing scientific support for the management of the HRWQ of the WR. It also indicated the significance of MC-EPA model's application.
\end{abstract}

Keywords: Monte Carlo; Health Risk; Water Quality; Triangular Fuzzy-Number; Mingshan County

\section{Introduction}

Along with the sustainable and speedy economic development, water contamination has become more serious with many toxic and harmful substances being discharged into the environment, posing long-term potential threat to the residents' health [1-3]. As a result, more attention is paid to health risk associated with water quality (HRWQ) [4-8]. How to implement qualitative and quantitative presentation of the contamination degree of those chemicals in water and to indicate directly the hazards to people by risk level become a key in the health risk assessment (HRA) associated with rural drinking water quality. Currently, most domestic researches applied the model recommended by United States Environmental Protection Agency (US EPA) to calculate the HRA for single water source, but little researches focused on the HRA for the regional water resources and the establishment of HRA parameter in county scale $[9,10]$. Setting rural areas as the studied object and on the basis of the specific drinking water condition of residents, this study analyzed the uncertainty of the model recommended by US EPA and implemented a comprehensive evaluation of the rural drinking water-related health risk to human health.

*Corresponding author.

\section{Materials and Methods}

\subsection{Sampling, Detection and Hazard Index Discrimination}

In 2010, 42 samples (Figure 1) were collected in 21 towns of Mingshan County, based on comprehensive consideration of the studied area's topography, hydrography, water system, the distribution of water-borne diseases and the types of water supply projects. Relevant chemical index in the 42 samples were detected and referring to the results, hazard index below the limit set by the Standard Examination Methods for Drinking Water is excluded and $\mathrm{Cr}(\mathrm{VI})$, iron, fluoride and nitrate are set as the index for water quality evaluation [10], among which $\mathrm{Cr}(\mathrm{VI})$ is set as carcinogenic index, and the detection value of indexes is shown in Table $\mathbf{1 .}$

In the investigation, the residents' exposure parameters (daily water intake rate, weight, height and age, etc.) were examined as well and 687 people were included, among which 591 are adults aging from 18 to 60 .

\subsection{Construction of MC-EPA Model}

The US EPA model [11] presented the long-term daily water intake amount and its corresponding carcinogenic and non-carcinogenic level. Actually, great uncertainty and fuzziness lie in the HRA due to the incomplete 


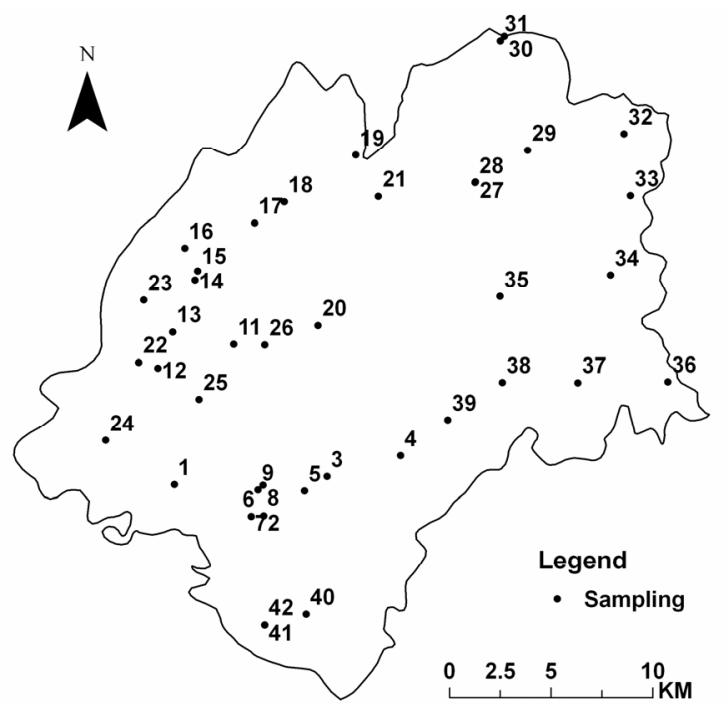

Figure 1. The distribution of sampling sites.

analysis, the extraction, applicability and assumption of model parameters, and the inaccuracy in measurement, sampling, experiment analysis, description and professional judgment as well as the spatial and temporal variations of chemicals' concentration both in surface water and ground water. At present, Monte Carlo Simulation is often used to deal with those uncertainly issues, it apply the method of probabilistic statistics to indicate the uncertainty of parameters, thus, it can present better risk identification and exposure assessment. And its analysis procedure is: define the statistical distribution law of input parameters; sample randomly parameters from its statistical distribution; repeat the model simulation by using parameters obtained by random sampling; analyze the output value to reach a reasonable result. Based on those steps, MC-EPA model is developed to implement the HRA associated with rural drinking water quality in Mingshan County.

\subsubsection{Stochastic Simulation of Parameters}

Parameters of health risk model comply with Gaussian distribution or approximate $[8,12]$. However, the insufficiency and incompleteness of data affected the HRA results. Recently, Triangular Fuzzy-number has been applied to match approximately the Gaussian distribution and some results were obtained [12]. In this study, parameters are transformed into Triangular Fuzzy-numbers, and then stochastic simulation of Triangular Fuzzy-numbers is carried out. In this way, many possible values of parameters that conform to some extent with the actual situation of the studied areas can be obtained.

$a_{1}, a_{2}, a_{3}\left(a_{1} \leq a_{2} \leq a_{3}\right)$ are defined correspondingly as the minimum value (MI), the most probable value (MP) and the maximum value (MA) of fuzzy variable $A$, therefore, $A$ can be represented by Triangular Fuzzy-
Table 1. Detection value of rural drinking water quality hazard index.

\begin{tabular}{|c|c|c|c|c|}
\hline Sample & $\mathrm{Fe}(\mathrm{mg} / \mathrm{L})$ & $\begin{array}{l}\mathrm{Cr}(\mathrm{VI}) \\
(\mathrm{mg} / \mathrm{L})\end{array}$ & $\begin{array}{l}\text { Nitrate } \\
(\mathrm{mg} / \mathrm{L})\end{array}$ & $\begin{array}{c}\text { Fluoride } \\
(\mathrm{mg} / \mathrm{L})\end{array}$ \\
\hline 1 & 0.04 & 0.04 & 11.73 & 0.97 \\
\hline 2 & 0 & 0.05 & 37.53 & 0.34 \\
\hline 3 & 0 & 0.05 & 11.86 & 0.88 \\
\hline 4 & 0.21 & 0.06 & 4.95 & 1.5 \\
\hline 5 & 0 & 0.06 & 8.95 & 0.23 \\
\hline 6 & 0.02 & 0.05 & 47.32 & 0.2 \\
\hline 7 & 0 & 0.05 & 7.18 & 0.49 \\
\hline 8 & 0 & 0.03 & 1.68 & 0.24 \\
\hline 9 & 0.13 & 0.03 & 5.7 & 1.4 \\
\hline 10 & 0.07 & 0.06 & 5.67 & 1.16 \\
\hline 11 & 4 & 0.11 & 17.5 & 0 \\
\hline 12 & 0 & 0.11 & 27.32 & 0.4 \\
\hline 13 & 0.03 & 0.12 & 11.2 & 0.24 \\
\hline 14 & 0.01 & 0.03 & 35.32 & 0 \\
\hline 15 & 0.01 & 0.08 & 9.16 & 0 \\
\hline 16 & 0.18 & 0.05 & 5.38 & 0 \\
\hline 17 & 0.2 & 0.11 & 1.2 & 0 \\
\hline 18 & 0.59 & 0.11 & 1.24 & 0 \\
\hline 19 & 0.01 & 0.15 & 44.95 & 0.12 \\
\hline 20 & 0 & 0.02 & 39.26 & 0 \\
\hline 21 & 0.03 & 0.1 & 9.87 & 0.27 \\
\hline 22 & 0 & 0.05 & 70.44 & 0.29 \\
\hline 23 & 0.01 & 0.05 & 30.42 & 0 \\
\hline 24 & 0 & 0.05 & 6.42 & 0 \\
\hline 25 & 0 & 0.06 & 3.47 & 0.05 \\
\hline 26 & 0 & 0.04 & 9.93 & 0.14 \\
\hline 27 & 0 & 0.06 & 11.87 & 0 \\
\hline 28 & 0 & 0.04 & 12.73 & 0.05 \\
\hline 29 & 0 & 0.08 & 28.2 & 0.16 \\
\hline 30 & 0.02 & 0.02 & 13.85 & 0.05 \\
\hline 31 & 0 & 0.03 & 4.4 & 0.03 \\
\hline 32 & 0.06 & 0.07 & 19.11 & 0.24 \\
\hline 33 & 0.17 & 0.06 & 29.33 & 0 \\
\hline 34 & 0.02 & 0.02 & 30.07 & 0 \\
\hline 35 & 0.48 & 0.14 & 1.18 & 0 \\
\hline 36 & 0.02 & 0.1 & 20.16 & 0.04 \\
\hline 37 & 0.05 & 0.05 & 65.3 & 0.24 \\
\hline 38 & 0.03 & 0.08 & 69.24 & 0.05 \\
\hline 39 & 0.02 & 0.06 & 67.51 & 0.36 \\
\hline 40 & 0.02 & 0.04 & 37.51 & 0.76 \\
\hline 41 & 0.04 & 0.02 & 37.02 & 0.34 \\
\hline 42 & 0.01 & 0.03 & 17.02 & 0.31 \\
\hline
\end{tabular}


number $\tilde{A}=\left\langle a_{1}, a_{2}, a_{3}\right\rangle$ [13] to which $\varphi_{(x)}$ is the membership function.

$$
\varphi_{(x)}=\left\{\begin{array}{l}
\left(x-a_{1}\right) /\left(a_{2}-a_{1}\right), a_{1} \leq x \leq a_{2} \\
\left(a_{3}-x\right) /\left(a_{3}-a_{2}\right), a_{2} \leq x \leq a_{3} \\
0, x<a_{1} \text { or } x>a_{3}
\end{array}\right.
$$

where, $x$ refers to the probable value of fuzzy variables in the universe.

Divide the square measure framed by axis $x$ and the curve of the membership function $\varphi_{(x)}$ by $\varphi_{(x)}$ to obtain the probable reliability density function of $\tilde{A}$ [14]:

$$
f_{\tilde{A}}(x)=\left\{\begin{array}{l}
2\left(x-a_{1}\right) /\left(\left(a_{2}-a_{1}\right)\left(a_{3}-a_{1}\right)\right) \\
a_{1} \leq x \leq a_{2} \\
2\left(a_{3}-x\right) /\left(\left(a_{3}-a_{2}\right)\left(a_{3}-a_{1}\right)\right) \\
a_{2} \leq x \leq a_{3} \\
0, x<a_{1} \text { or } x>a_{3}
\end{array}\right.
$$

Transform $f_{\tilde{A}}(x)$ into probability distribution function and obtain the stochastic simulation formula of $x$ by the inverse transform method $[14,15]$ :

$$
x=\left\{\begin{array}{l}
a_{1}+\left(u\left(a_{2}-a_{1}\right)\left(a_{3}-a_{1}\right)\right)^{0.5}, \\
u \leq\left(a_{2}-a_{1}\right) /\left(a_{3}-a_{1}\right) \\
a_{3}-\left((1-u)\left(a_{3}-a_{2}\right)\left(a_{3}-a_{1}\right)\right)^{0.5}, \\
u>\left(a_{2}-a_{1}\right) /\left(a_{3}-a_{1}\right)
\end{array}\right.
$$

where, $u$ refers to uniform random numbers within the interval of $[0,1]$, which can be obtained by Matlab using rand order.

\subsubsection{Monte Carlo-Based Health Risk Value Calculation}

Based on the assumption that the state of water quality is $R$ in the evaluation system for HRWQ and the given limit value of water quality standard is $R_{Z}$, then the HRWQ can be defined as:

$$
P_{Z}=P\left(R \geq R_{Z}\right)
$$

where, $R$ refers to both $C R$ and hazard index $(H I)$ and its calculation formula is as following:

$$
\begin{aligned}
R= & \frac{\left\langle C_{1}, C_{2}, C_{3}\right\rangle \times\left\langle I_{R 1}, I_{R 2}, I_{R 3}\right\rangle \times\left\langle E_{F 1}, E_{F 2}, E_{F 3}\right\rangle}{\left\langle B_{W 1}, B_{W 2}, B_{W 3}\right\rangle} \\
& \times \frac{\left\langle E_{D 1}, E_{D 2}, E_{D 3}\right\rangle}{A_{T}} \times S_{F} \\
H I= & \frac{\left\langle C_{1}, C_{2}, C_{3}\right\rangle \times\left\langle I_{R 1}, I_{R 2}, I_{R 3}\right\rangle \times\left\langle E_{F 1}, E_{F 2}, E_{F 3}\right\rangle}{\left\langle B_{W 1}, B_{W 2}, B_{W 3}\right\rangle} \\
& \times \frac{\left\langle E_{D 1}, E_{D 2}, E_{D 3}\right\rangle}{A_{T} \times R_{F D}}
\end{aligned}
$$

where, $P_{Z}$ can be taken as the reliability when the water quality state $R$ exceeds the standard limit $R_{Z}$. $\left\langle C_{1}, C_{2}, C_{3}\right\rangle$ is the stochastic simulation value, where $C_{1}$, $C_{2}, C_{3}$ refer correspondingly to the MI, the MP and the MA of pollutants concentration; $\left\langle I_{R 1}, I_{R 2}, I_{R 3}\right\rangle$ is the stochastic simulation value where $I_{\mathrm{R} 1}, I_{\mathrm{R} 2}, I_{\mathrm{R} 3}$ correspondingly refer to the MI, the MPV and the MA of water drinking rate; $\left\langle E_{F 1}, E_{F 2}, E_{F 3}\right\rangle$ is stochastic simulation value (SSV), where $E_{F 1}, E_{F 2}, E_{F 3}$ state correspondingly to the MI, the MP and the MA of the exposure frequency; $\left\langle E_{D 1}, E_{D 2}, E_{D 3}\right\rangle$ is the $\mathrm{SSV}$, where $E_{D 1}, E_{D 2}$, $E_{D 3}$ refer correspondingly to the MI, the MP and the MA of the exposure duration; $\left\langle B_{W 1}, B_{W 2}, B_{W 3}\right\rangle$ is the SSV, where $B_{W 1}, B_{W 2}$, and $B_{W 3}$ correspondingly refer to the MI, the MP and the MA of the weight; $A_{T}$ refers to the average time (the suggesting value is $70 \mathrm{a} \times 365 \mathrm{~d} \cdot \mathrm{a}^{-1}$ ); $R_{F D}$ is the referring dose $\left(\mathrm{mg} \cdot \mathrm{kg}^{-1} \cdot \mathrm{d}^{-1}\right)$.

By applying the stochastic simulation of parameters, the simulation sequence of parameters $\{x \mid i=1,2,3, \cdots, m\}$ in the evaluation system for HRWQ can be obtained from Equation (3) and the simulation sequence of water quality state $\left\{R_{i} \mid i=1,2,3, \cdots, m\right\}$ can be obtained from Equations (5) and (6), and $m$ is the simulation times. Researches [15] indicated that the more times the experiment is repeated, the frequency distribution of $R$ ws closer to actual probability, therefore, the value of $m$ is set where the frequency distribution reaches convergence and $m_{Z}$ refers to the times $R$ exceeds the standard limit $R_{Z}$.

Therefore, the reliability of the interval of HRWQ is:

$$
P_{Z}=m_{\mathrm{Z}} / m
$$

\subsection{Health Risk Assessment}

Information of chemicals (Fe, $\mathrm{Cr}(\mathrm{VI})$, nitrate and fluoride), weight and drinking water ingestion rate was dealt with according to the investigation on the exposure parameters of residents who rely on the 42 water resources in Mingshan County and by applying the MC-EPA model. The results showed as Table 2 .

Table 2. Exposure parameters statistics.

\begin{tabular}{ccccc}
\hline $\begin{array}{c}\text { Exposure } \\
\text { parameters }\end{array}$ & $\begin{array}{c}\text { Average } \\
\text { value }\end{array}$ & MAV & MIV & $\begin{array}{c}\text { Triangular } \\
\text { fuzzy-number }\end{array}$ \\
\hline Fe & 0.15 & 4 & 0 & $<0,0.15,4>$ \\
Cr(VI) & 0.06 & 0.15 & 0.02 & $<0.02,0.06,0.15>$ \\
Nitrate & 22.15 & 70.44 & 1.18 & $<1.18,22.15,70.44>$ \\
Fluoride & 0.28 & 1.5 & 0 & $<0,0.28,1.5>$ \\
$I_{R}$ & 1.5 & 4 & 0.85 & $<0.85,1.5,4>$ \\
Weight & 61 & 89.3 & 42.4 & $<42.4,61,89.3>$ \\
$\begin{array}{c}\text { Exposure } \\
\text { frequency }\end{array}$ & 340 & 360 & 320 & $<320,340,360>$ \\
\hline
\end{tabular}


In the data dealing process, data too far from the rest is excluded and the average value, the MA and the MI in the investigation are set correspondingly as the MP, the MA and the MI of the Triangular Fuzzy-number. The average health risk caused by various chemicals to individuals and the reliability of the health risk can be obtained from Equations (3) and (4), as is shown in Tables 3 and 4.

Referring to the above results obtained from the simulation experiments, the results will reach convergence when the experiment is simulated as many as 100,000 times, i.e. according to the MC-EPA model, 100,000 times of simulation experiments can obtain the CR, NCR and the reliability of the risk interval, as is shown in Tables 5 and 6.

\section{Results Analysis}

\subsection{NCR Assessment}

According to the definition of hazard index, the risk standard of non-carcinogenic chronic toxic effect can be set as "1". Table 3 indicates that the average hazard index of the total water quality in Mingshan County is 0.6681 below the risk standard and the corresponding reliability of total hazard index within interval $0-0.1$, interval $0.1-0.2$, interval $0.2-0.5$, interval $0.5-1$ and interval greater than 1 is $29.39 \%, 21.87 \%, 39.43 \%$, $9.48 \%$ and 0 . According to the hazard index value, they can be ranked as follows: $\mathrm{Cr}(\mathrm{VI})>$ nitrate $>$ fluoride $>$ Fe. The corresponding average hazard index of $\mathrm{Cr}(\mathrm{VI})$, nitrate, fluoride and $\mathrm{Fe}$ is $0.2983,0.2101,0.0894$ and 0.0703 .

As Table 5 shown, the hazard index of samples No.11, $12,19,22,37,38$ and 39 exceed the standard limit " 1 ", and their corresponding reliability are $21.24 \%, 16.93 \%$, $98.88 \%, 50.69 \%, 26.7 \%, 73.46 \%$ and $63.45 \%$. That $\mathrm{Cr}(\mathrm{VI})$ and nitrate exceed the standard is the main cause for the excessive hazard index. And the hazard index of sample 40 is at the critical point of 0.9227 . It is highly recommend that relevant administrations implement monitoring, investigation and management of WR whose hazard index are at the critical point as well as WR that

Table 3. Calculation results of total NCR.

\begin{tabular}{|c|c|c|c|c|c|c|c|c|c|}
\hline \multirow{2}{*}{$\begin{array}{l}\text { Experiment } \\
\text { times }\end{array}$} & \multirow{2}{*}{$\begin{array}{l}\text { Pollutants } \\
\quad(\mathrm{ml} / \mathrm{L})\end{array}$} & \multicolumn{3}{|c|}{ NCR } & \multicolumn{5}{|c|}{ Reliability of NCR } \\
\hline & & Average value & MAV & MIV & $(0,0.1)$ & $(0.1,0.2)$ & $(0.2,0.5)$ & $(0.5,1)$ & $>1$ \\
\hline \multirow{4}{*}{30000} & $\mathrm{Fe}$ & 0.0642 & 0.4803 & 0.0013 & 0.7260 & 0.2466 & 0.0274 & 0 & 0 \\
\hline & $\mathrm{Cr}(\mathrm{VI})$ & 0.3014 & 0.7231 & 0.0914 & 0.0010 & 0.0799 & 0.6867 & 0.2323 & 0 \\
\hline & nitrate & 0.2145 & 0.7235 & 0.0273 & 0.0601 & 0.2134 & 0.5828 & 0.1437 & 0 \\
\hline & Total dose & 0.6798 & 2.3556 & 0.1223 & 0.2920 & 0.2209 & 0.3946 & 0.0940 & 0 \\
\hline \multirow{4}{*}{50000} & $\mathrm{Fe}$ & 0.0712 & 0.4867 & 0.0015 & 0.7327 & 0.2388 & 0.0284 & 0 & 0 \\
\hline & $\mathrm{Cr}(\mathrm{VI})$ & 0.2984 & 0.7325 & 0.0931 & 0.0012 & 0.0795 & 0.6844 & 0.2349 & 0 \\
\hline & nitrate & 0.2018 & 0.7326 & 0.0265 & 0.0585 & 0.2138 & 0.5849 & 0.1428 & 0 \\
\hline & Total dose & 0.6608 & 2.3833 & 0.1232 & 0.2935 & 0.2189 & 0.3932 & 0.0944 & 0 \\
\hline \multirow{5}{*}{100000} & $\mathrm{Fe}$ & 0.0703 & 0.4803 & 0.0013 & 0.7328 & 0.2387 & 0.0284 & 0 & 0 \\
\hline & $\mathrm{Cr}(\mathrm{VI})$ & 0.2983 & 0.7327 & 0.0901 & 0.0011 & 0.0793 & 0.6842 & 0.2354 & 0 \\
\hline & nitrate & 0.2101 & 0.7235 & 0.0263 & 0.0603 & 0.2132 & 0.5828 & 0.1437 & 0 \\
\hline & fluoride & 0.0894 & 0.4315 & 0.0021 & 0.3815 & 0.3435 & 0.2816 & 0 & 0 \\
\hline & Total dose & 0.6681 & 2.368 & 0.1198 & 0.2939 & 0.2187 & 0.3943 & 0.0948 & 0 \\
\hline
\end{tabular}

Table 4. Calculation results of total CR.

\begin{tabular}{|c|c|c|c|c|c|c|c|c|}
\hline \multirow{2}{*}{$\begin{array}{l}\text { Pollutants } \\
(\mathrm{mg} / \mathrm{L})\end{array}$} & \multirow{2}{*}{$\begin{array}{c}\text { Experiment } \\
\text { times }\end{array}$} & \multicolumn{3}{|c|}{$\mathrm{CR}\left(10^{\wedge}(-6)\right)$} & \multicolumn{4}{|c|}{ Reliability of NCR interval } \\
\hline & & AV & MAV & MIV & $(1,5) \times 10^{-6}$ & $(5,10) \times 10^{-6}$ & $(10,50) \times 10^{-6}$ & $>50 \times 10^{-6}$ \\
\hline \multirow{3}{*}{$\mathrm{Cr}(\mathrm{VI})$} & 30,000 & 6.67 & 21.71 & 2.16 & 0.1213 & 0.5963 & 0.2824 & 0 \\
\hline & 50,000 & 9.75 & 23.86 & 2.14 & 0.1221 & 0.5890 & 0.2889 & 0 \\
\hline & 100,000 & 9.81 & 23.91 & 2.09 & 0.1221 & 0.5890 & 0.2889 & 0 \\
\hline
\end{tabular}


Table 5. Calculation results of NCR of the 42 water resources.

\begin{tabular}{|c|c|c|c|c|c|c|c|c|c|c|}
\hline \multirow{2}{*}{ Sample } & \multicolumn{5}{|c|}{$\mathrm{NCR}$} & \multicolumn{5}{|c|}{ Reliability of NCR interval } \\
\hline & $\mathrm{Fe}$ & $\mathrm{Cr}(\mathrm{VI})$ & nitrate & fluoride & Total & $(0,0.1)$ & $(0.1,0.2)$ & $(0.2,0.5)$ & $(0.5,1)$ & $>1$ \\
\hline 1 & 0.0021 & 0.2134 & 0.1173 & 0.2587 & 0.5915 & 0 & 0 & 0.1691 & 0.8309 & 0 \\
\hline 2 & 0 & 0.2734 & 0.3848 & 0.093 & 0.7512 & 0 & 0 & 0 & 1 & 0 \\
\hline 3 & 0 & 0.3 & 0.1334 & 0.264 & 0.6975 & 0 & 0 & 0.0779 & 0.9222 & 0 \\
\hline 4 & 0.0115 & 0.3288 & 0.0509 & 0.411 & 0.8023 & 0 & 0 & 0 & 1 & 0 \\
\hline 5 & 0 & 0.319 & 0.0892 & 0.0611 & 0.4694 & 0 & 0 & 0.9125 & 0.0875 & 0 \\
\hline 6 & 0.001 & 0.2621 & 0.4651 & 0.0524 & 0.7807 & 0 & 0 & 0 & 1 & 0 \\
\hline 7 & 0 & 0.2759 & 0.0743 & 0.1352 & 0.4854 & 0 & 0 & 0.9175 & 0.0825 & 0 \\
\hline 8 & 0 & 0.1299 & 0.0136 & 0.0519 & 0.1954 & 0 & 0.1326 & 0.8674 & 0 & 0 \\
\hline 9 & 0.0064 & 0.1467 & 0.0522 & 0.3422 & 0.5474 & 0 & 0 & 0.1503 & 0.8497 & 0 \\
\hline 10 & 0.0036 & 0.3071 & 0.0544 & 0.2969 & 0.662 & 0 & 0 & 0 & 1 & 0 \\
\hline 11 & 0.2217 & 0.6096 & 0.1819 & 0 & 1.0132 & 0 & 0 & 0 & 0.7876 & 0.2124 \\
\hline 12 & 0 & 0.6076 & 0.283 & 0.1105 & 1.0011 & 0 & 0 & 0 & 0.8307 & 0.1693 \\
\hline 13 & 0.0015 & 0.6132 & 0.1073 & 0.0613 & 0.7833 & 0 & 0 & 0 & 1 & 0 \\
\hline 14 & 0.0005 & 0.1519 & 0.3353 & 0 & 0.4877 & 0 & 0 & 0.5651 & 0.4349 & 0 \\
\hline 15 & 0.0005 & 0.3982 & 0.0855 & 0 & 0.4842 & 0 & 0 & 0.5294 & 0.4706 & 0 \\
\hline 16 & 0.0092 & 0.2566 & 0.0518 & 0 & 0.3177 & 0 & 0 & 1 & 0 & 0 \\
\hline 17 & 0.0086 & 0.4739 & 0.0097 & 0 & 0.4922 & 0 & 0 & 0.1105 & 0.8895 & 0 \\
\hline 18 & 0.0256 & 0.4778 & 0.0101 & 0 & 0.5135 & 0 & 0 & 0.0444 & 0.9556 & 0 \\
\hline 19 & 0.0005 & 0.7345 & 0.4127 & 0.0294 & 1.1771 & 0 & 0 & 0 & 0.0112 & 0.9888 \\
\hline 20 & 0 & 0.0929 & 0.3419 & 0 & 0.4347 & 0 & 0 & 0.6787 & 0.3213 & 0 \\
\hline 21 & 0.0017 & 0.5766 & 0.1067 & 0.0778 & 0.7629 & 0 & 0 & 0 & 1 & 0 \\
\hline 22 & 0 & 0.2592 & 0.6847 & 0.0752 & 1.019 & 0 & 0 & 0 & 0.4931 & 0.5069 \\
\hline 23 & 0.0005 & 0.2588 & 0.2952 & 0 & 0.5545 & 0 & 0 & 0.246 & 0.754 & 0 \\
\hline 24 & 0 & 0.2478 & 0.0596 & 0 & 0.3074 & 0 & 0 & 1 & 0 & 0 \\
\hline 25 & 0 & 0.3194 & 0.0346 & 0.0133 & 0.3674 & 0 & 0 & 1 & 0 & 0 \\
\hline 26 & 0 & 0.2268 & 0.1056 & 0.0397 & 0.3721 & 0 & 0 & 1 & 0 & 0 \\
\hline 27 & 0 & 0.2574 & 0.0955 & 0 & 0.3529 & 0 & 0 & 0.9876 & 0.0124 & 0 \\
\hline 28 & 0 & 0.2229 & 0.133 & 0.0139 & 0.3699 & 0 & 0 & 1 & 0 & 0 \\
\hline 29 & 0 & 0.435 & 0.2875 & 0.0435 & 0.7659 & 0 & 0 & 0 & 1 & 0 \\
\hline 30 & 0.0011 & 0.1084 & 0.1407 & 0.0135 & 0.2638 & 0 & 0 & 1 & 0 & 0 \\
\hline 31 & 0 & 0.1301 & 0.0358 & 0.0065 & 0.1724 & 0 & 0 & 0.4563 & 0 & 0 \\
\hline 32 & 0.0035 & 0.4106 & 0.2102 & 0.0704 & 0.6948 & 0 & 0 & 0.041 & 0.959 & 0 \\
\hline 33 & 0.0083 & 0.293 & 0.2685 & 0 & 0.5698 & 0 & 0 & 0.0704 & 0.9296 & 0 \\
\hline 34 & 0.0011 & 0.108 & 0.3045 & 0 & 0.4136 & 0 & 0 & 1 & 0 & 0 \\
\hline 35 & 0.0259 & 0.7548 & 0.0119 & 0 & 0 & 0 & 0 & 0 & 1 & 0 \\
\hline 36 & 0.0009 & 0.4392 & 0.166 & 0.0088 & 0.6149 & 0 & 0 & 0 & 1 & 0 \\
\hline 37 & 0.0027 & 0.2725 & 0.6672 & 0.0654 & 1.0077 & 0 & 0 & 0 & 0.733 & 0.267 \\
\hline 38 & 0.0016 & 0.4347 & 0.7055 & 0.0136 & 1.1554 & 0 & 0 & 0 & 0.2654 & 0.7346 \\
\hline 39 & 0.0012 & 0.3478 & 0.7338 & 0.1043 & 1.1871 & 0 & 0 & 0 & 0.3655 & 0.6345 \\
\hline 40 & 0.0012 & 0.2485 & 0.4369 & 0.2361 & 0.9227 & 0 & 0 & 0 & 1 & 0 \\
\hline 41 & 0.002 & 0.1017 & 0.3531 & 0.0865 & 0.5433 & 0 & 0 & 0.2545 & 0.7455 & 0 \\
\hline 42 & 0.0006 & 0.1744 & 0.1855 & 0.0901 & 0.4506 & 0 & 0 & 1 & 0 & 0 \\
\hline
\end{tabular}


Table 6. Calculation results of CR of water resources.

\begin{tabular}{cccccc}
\hline Sample & CR $\left(10^{-6}\right)$ & sample & CR $\left(10^{-6}\right)$ & Sample & CR $\left(10^{-6}\right)$ \\
\hline 1 & 4.36 & 15 & 8.85 & 29 & 8.92 \\
2 & 5.45 & 16 & 5.54 & 30 & 2.17 \\
3 & 5.43 & 17 & 11.97 & 31 & 3.36 \\
4 & 6.56 & 18 & 12.32 & 32 & 7.53 \\
5 & 6.62 & 19 & 23.45 & 33 & 6.42 \\
6 & 5.27 & 20 & 2.23 & 34 & 2.46 \\
7 & 5.31 & 21 & 10.36 & 35 & 22.87 \\
8 & 3.58 & 22 & 5.38 & 36 & 10.32 \\
9 & 3.41 & 23 & 5.43 & 37 & 5.91 \\
11 & 6.61 & 24 & 5.48 & 39 & 8.75 \\
12 & 12.34 & 25 & 6.37 & 49 & 6.81 \\
14 & 11.96 & 26 & 4.42 & 41 & 4.62 \\
\end{tabular}

Note: Reliability of NCR is not listed in table 6 for the insufficient space.

fail to meet the standard.

\subsection{CR Assessment}

Risk management experience abroad indicates that it is acceptable the chemicals in drinking water run a CR of 1 $\times 10^{-6}$ to $1 \times 10^{-4}[9,14]$. Setting the strictest acceptable risk value $1 \times 10^{-6}$ as the evaluation standard, and referring to Table 4, it can be seen that the total CR caused by pollutants in Mingshan County is $9.81 \times 10^{-6}$, exceeding 9.81 times the standard and according to the MC-EPA model, the corresponding reliability of the total CR that exceed the standard 1 - 5 times, 5 - 10 times and $10-50$ times are $12.21 \%, 58.9 \%$ and $28.89 \%$. Referring to Table 6, the CR of all the $42 \mathrm{WR}$ is above the standard, exceeding 1.17 to 22.45 times of the limit. Among the water resources, the CR of sample19 and 35 is 20 times over the standard. It is strongly suggested that relevant administrations implement an overall investigation on the causes for the $\mathrm{Cr}(\mathrm{VI})$ contamination of the drinking water quality in Mingshan County and carry out effective solution to solve the $\mathrm{Cr}(\mathrm{VI})$ pollution issue.

\section{Conclusion}

The NCR of the total water quality in Mingshan County is below "1", which means the drinking water as a whole won't have non-carcinogenic chronic toxic effect on the residents. However, the total NCR of sample No.11, 12, 19, 22, 37, 38 and 39 exceeds " 1 ". Protection measures of relevant administrations are in urgent need. The CR of the $42 \mathrm{WR}$ all exceeds the standard $10^{-6}$ recommended by the US EPA, i.e. drinking water in Mingshan County is mainly contaminated by excessive $\mathrm{Cr}(\mathrm{VI})$, therefore it is highly recommended that relevant administrations lay emphasis on the investigation on causes for $\mathrm{Cr}(\mathrm{VI})$ contamination and implement measures to protect the WR and to ensure the drinking water safety. Many nondeterministic issues present in the evaluation system for HRWQ, such as the randomness and fuzziness of the information and the model. In this study, the information of those chemicals in water is transformed in to triangularfuzzy number and based on the data of chemicals to collect, plenty of simulation experiments are carried out to lower randomness of the HRA system. The MC-EPA model is developed by the application of the Monte Carlo method combined with the US EPA model. The evaluation system for the HAWQ of Mingshan County indicates the significance of the application of MC-EPA.

\section{REFERENCES}

[1] L. Y. Chai, Z. X. Wang, Y. Y. Wang, et al., "Ingestion Risks of Metals in Groundwater Based on TIN Model and Dose-Response Assessment: A Case Study in the Xiangjiang Watershed, Central-South China," Science of the Total Environment, Vol. 408, 2010, pp. 3118-3124.

[2] E. Topuz, I. Talinli and E. Aydin, "Integration of Environmental and Human Health Risk Assessment for Industries Using Hazardous Materials: A Quantitative Multi Criteria Approach for Environmental Decision Makers," Environment International, Vol. 37, 2011, pp. 393-403.

[3] J. Zhou, Y. You, Z. P. Bai, et al., "Health Risk Assessment of Personal Inhalation Exposure to Volatile Organic Compounds in Tianjin, China," Science of the Total Environment, Vol. 409, No. 3, 2011, pp. 452-459. doi:10.1016/j.scitotenv.2010.10.022

[4] D. C. Dante, P. Paulina and M. Nestor, "Exposure to In- 
organic Arsenic in Drinking Water and Total Arsenic Concentration in a Chilean Population," Environmental Research, Vol. 98, No. 2, 2005, pp. 151-159. doi:10.1016/i.envres.2005.02.007

[5] K. L. Hu, Y. F. Huang, H. Li, et al., "Spatial Variability of Shallow Groundwater Level, Electrical Conductivity and Nitrate Concentration, and Risk Assessment of Nitrate Contamination in North China Plain," Environmental International, Vol. 31, No. 6, 2005, pp. 896-903. doi:10.1016/j.envint.2005.05.028

[6] C. H. Fan, G. S. Wang, Y. C. Chen, et al., "Risk Assessment of Exposure to Volatile Organic Compounds in Groundwater in Taiwan," Science of Total Environment, Vol. 407, No. 7, 2009, pp. 2165-2174. doi:10.1016/j.scitotenv.2008.12.015

[7] H. J. Jeong, W. T. Hwang, E. H. Kim, et al., "Radiological Risk Assessment for an Urban Area: Focusing on a Drinking Water Contamination," Annual Nuclear Energy, Vol. 36, 2009, pp. 1313-1318.

[8] R. Z. Li, M. Shigeki, T. Q. Hong, et al., "Fuzzy Model for Two-Dimensional River Water Quality Simulation under Sudden Pollutants Discharged," Journal of Hydrodynogy, Vol. 19, 2007, pp. 434-441.

[9] F. Q. Ni, G. D. Liu, S. C. Yang, et al., "Heath Risk Assessment Associated with the Rural Drinking Water Quality in the Western Edge of the Sichuan Basin," Progress in Natural Science, Vol. 19, 2009, pp. 1281-1288 (in Chinese).

[10] F. Q. Ni, G. D. Liu, Y. S. Tan, et al., "Spatial Variation of Health Risk of Groundwater for Drinking Water Supply in Mingshan County, Ya'an City, China," Water Science and Engineering, Vol. 3, No. 4, 2010, pp. 454-466.

[11] US EPA, "Risk Assessment Guidance for Superfund in Human Health Evaluation Manual (Part A)," EPA/541/ 1-89/002, December 1989, pp. 193-198.

[12] R. Zou and W. S. Lung, "Uncertainty Analysis for a Dynamic Phosphorus Model with Fuzzy Parameters," Water Quality and Ecosystem Modeling, Vol. 1, No. 1-4, 2000, pp. 237-252. doi:10.1023/A:1013946902263

[13] E. G. Ronald and E. Y. Robert, "Analysis of the Error in the Standard Approximation Used for Multiplication of Triangular and Trapezoidal Fuzzy Number and the Development of a New Approximation," Fuzzy Sets and Systems, Vol. 91, No. 1, 1997, pp. 1-13. doi:10.1016/S0165-0114(96)00118-2

[14] J. L. Jin, K. Y. Wu and R. Z. Li, "The Stochastic Simulation and Triangular Fuzzy Number Coupling Model of Water Environment Risk Evaluation," Journal of Hydraulic Engineering, Vol. 39, 2008, pp. 1257-1261 (in Chinese).

[15] W. S. Wang, J. L. Jin and Y. Q. Li, "Stochastic Simulation Method for Hydrology and Water Resource," Sichuan University Press, Chengdu, 2007 (in Chinese). 